\title{
IDENTIFICAÇÃO DE PROGÊNIES DE ARROZ RESISTENTES À BRUSONE NO ESTADO DE SÃO PAULO, EM 1976/77 (')
}

\author{
JACIRO SOAVE $\left({ }^{2}, 7\right.$ ), LUIZ ERNESTO AZZINI $\left({ }^{3,7}\right)$, OCTĂVIO BENTO DE ALMEIDA \\ CAMARGO $\left({ }^{4}, 7\right)$, ARMANDO PETTINELLI JÚNIOR $\left({ }^{5,7}\right)$ e MAURO SAKAI $\left({ }^{6,7}\right)$
}

\begin{abstract}
RESUMO
Este trabalho apresenta os resultados das pesquisas realizadas para a avaliação da resistência à brusone (Pyricularia oryzae Cav.) dos principais materiais de sequeiro e irrigado do programa de melhoramento genético do Instituto Agronômico do Estado de São Paulo, e de genótipos exóticos, introduzidos de diversos países, visando à obtenção de cultivares de arroź resistentes àquela limitante doença fúngica. Os testes foram realizados em condiçōes de campo, em canteiros padronizados para reação uniforme a $P$. oryzae, e a avaliação das plantas foi feita através da observação dos sintomas visuais deixados pela doença, aos quais foram atribuídas notas de 1 a 7 , conforme a escala de notas adotadas no "Symposium on the rice blast disease", em 1963. Sessenta e três germoplasmas de arroz de sequeiro e trinta de cultivo irrigado foram testados quanto à resistência à brusone na folha, nas seguintes localidades paulistas: Itararé, Mococa, Pariquera-Açu, Pindamonhangaba, Pindorama e Ribeirâo Preto. Foram ainda avaliados 102 genótipos exóticos de arroz visando à detecçầo de fontes de resistência à brusone nas mesmas localidades, além de Campinas. Somente cinco cultivares de sequeiro, GS-73-164, GS-73-165, GS-73-94, IAC-25 e
\end{abstract}

( ${ }^{1}$ ) Trabalho apresentado no VII Congresso Paulista de Fitopatologia, realizado em Botucatu (SP), 23-25 de janeiro de 1984. Recebido para publicação em 31 de maio de 1984. Os autores registram seus agradecimentos aos colegas Túlio Ribeiro Rocha, Rui Ribeiro dos Santos, Nelson C. Schmidt, Joāo Aloisi Sobrinho e Guido De Sordi.

$\left(^{2}\right)$ Seção de Microbiologia Fitotécnica, Instituto Agronômico (IAC), Caixa Postal 28 - 13100 , Campinas, SP.

$\left({ }^{3}\right)$ Seção de Genética, IAC.

$\left({ }^{4}\right)$ Seção de Arroz e Cereais de Inverno, IAC.

$\left({ }^{5}\right)$ Estação Experimental de Tatui, IAC.

(6) Estação Experimental de Pariquera-Açu, IAC.

( ${ }^{7}$ ) Com bolsa de suplementação do CNPq. 
GS-73-17, e dois cultivares de arroz irrigado, IAC-120 e Pinda F-3-7, embora suscetíveis, apresentaram comportamento satisfatório quanto à brusone. Dos genótipos exóticos testados, vinte e sete foram indicados como fontes de resistência à brusone no Estado de São Paulo.

Termos de indexação: arroz; brusone; resistência genética.

\section{INTRODUÇÃO}

Os prejuízos causados pela brusone (Pyricularia oryzae Cav.), uma das principais doenças do arroz, atingem grande importância quando se considera a área plantada e a produção nacional (FRATTINI \& SOAVE, 1974, e PRABHU, 1980).

No Estado de São Paulo, os melhores cultivares de arroz adaptados para as condições de sequeiro e a maioria dos cultivares para plantio irrigado são suscetíveis à brusone.

Os programas de melhoramento genético do arroz visando à obtenção de cultivares resistentes à brusone tornam-se complexos em vista da grande variabilidade do patógeno, levando a concluir que.a criação de cultivares com resistência horizontal ou poligênica seria a solução ideal. Todavia, pouco se conhece em relação à resistência horizontal do arroz à brusone (PRABHU et alii, 1982). Segundo OU (1972), a obtenção de cultivares resistentes leva ao aparecimento de novas raças de patógeno, havendo necessidade da deteç̧ão de novas fontes com espectro amplo de resistência, e, conforme NELSON (1973), a resistência vertical ou monogênica de amplo espectro pode ser incorporada facilmente aos cultivares comerciais com o inconveniente de não ser duradoura por induzir o aparecimento de novas raças patogênicas do fungo, pela elevada pressão seletiva exercida. $\mathrm{O}$ emprego de multilíneas, como sugerido por BROWNING \& FREY (1969), consistindo na mistura de linhagens melhoradas com resistência monogênica a diversas raças do patógeno, poderia ser uma boa alternativa.

As reações varietais à brusone alteram-se com a região e com a época do ano numa mesma região, conforme SOAVE \& AZZINI (1978) e OU (1980), indicando que os testes devem ser feitos no maior número possível de locais para expor os cultivares em teste ao maior número possível de raças. Essa variação de reações cria enormes problemas ao melhoramento genético do arroz visando à obtenção de resistência em vista da grande variabilidade da ação patogênica do fungo, conforme demonstrado genericamente por QUAMARUZZAMAN \& OU (1970) e, em nossas condições, por BEDENDO et alii (1979), AMARAL et alii (1979) e RIBEIRO (1980). 
Este trabalho apresenta os resultados das pesquisas realizadas para a avaliação da resistência à brusone dos principais germoplasmas de sequeiro e irrigado do programa de melhoramento genético de arroz do Instituto Agronômico do Estado de São Paulo, e de material exótico, visando detectar fontes de resistência à brusone.

\section{MATERIAL E MÉTODOS}

Os testes de resistência foram realizados através do método de inoculação natural em canteiros padronizados para reação uniforme à brusone, proposto pelo INTERNATIONAL RICE RESEARCH INSTITUTE (1963). Cada material a ser testado foi semeado numa linha de $50 \mathrm{~cm}$ de comprimento, com espaçamento de $10 \mathrm{~cm}$ entre linhas. A cada duas linhas de material em teste, intercalou-se uma linha do cultivar IAC-162, controle suscetível em nossas condiçбes. Após dez linhas de material em teste, foi colocada uma linha do 'IR-841', controle resistente que, por sua vez, ficou entre duas linhas do cultivar suscetível. Em ambos os lados de cada canteiro, foram plantadas três linhas de bordadura do material suscetível, espaçadas $10 \mathrm{~cm}$ entre si e distantes $10 \mathrm{~cm}$ das extremidades das linhas dos germoplasmas em teste.

Foram plantados $5 \mathrm{~g}$ de sementes por linha de $50 \mathrm{~cm}$ e a adubação foi feita na base de $240 \mathrm{~kg}$ de $\mathrm{N}$ por hectare, na forma de sulfato de amônio, aplicado $1 / 3$ no plantio, $1 / 3$ em cobertura após 15 dias da germinação e $1 / 3$ após 25 dias da germinação, além de $50 \mathrm{~kg}$ de $\mathrm{P}_{2} \mathrm{O}_{5}$ por hectare, na forma de superfosfato simples, por ocasião do plantio.

Os canteiros foram protegidos contra pássaros com rede de náilon até 15 dias após a germinação e irrigados pelo menos uma vez ao dia.

Os germoplasmas de arroz em processo de melhoramento genético no Instituto Agronômico, tanto os de sequeiro como os de condições irrigadas, foram testados nas seguintes localidades: Itararé, Mococa, PariqueraAçu, Pindamonhangaba, Pindorama e Ribeirão Preto, e os materiais exóticos, também em Campinas.

A avaliação da suscetibilidade dos materiais foi feita através da leitura dos sintomas nas folhas, obedecendo à escala de notas aprovada no "Symposium on the rice blast disease" (INTERNATIONAL. ., 1963): Nota 1: altamente resistente, com lesões de diâmetro menor que $0,5 \mathrm{~mm}$, em forma de cabeça de alfinete, tipo não-necrótico e de coloração marrom; 2: resistente, com lesões de diâmetro entre 0,5 e $1,0 \mathrm{~mm}$ em pontos maiores, tipo não-necrótico e coloração marrom; 3: medianamente resistente, com lesões de diâmetro entre 1 e $2 \mathrm{~mm}$, de forma arredondada, tipo necrótico 
e de coloração cinza com halo marrom; 4: medianamente suscetível, com lesões de $5 \mathrm{~mm}$ ou mais de diâmetro e 1 a $2 \mathrm{~cm}$ de comprimento, de forma elíptica, tipo necrótico, de coloração cinza e com menos de $5 \%$ da área foliar atingida; 5: suscetivel com as características da nota 4, mas as lesões se coalescem atacando até $25 \%$ da área foliar; 6: bastante suscetível, com as características da nota 4 com até $50 \%$ da área foliar atacada; 7: altamente suscetível, com as características da nota 4 , mas com área foliar atacada acima de $50 \%$. As leituras foram efetuadas, em todas as localidades, aos 35-37 dias após a germinação.

\section{RESULTADOS E DISCUSSÃO}

As reações dos 63 cultivares e progênies de arroz de sequeiro à brusone, em seis localidades paulistas, podem ser observadas no quadro 1 .

Dos cultivares em plantio comercial, o IAC-25, de ciclo precoce, mostrou-se o menos suscetível, apresentando reação de suscetibilidade (nota igual ou superior a 5) em $50 \%$ dos testes realizados, com nota média igual a 5,00. O 'Pratão Precoce', de origem mais antiga, mas ainda plantado no Estado, apresentou média geral igual a 5,50. O 'IAC-47' e 'IAC-1246', de ciclo médio, apresentaram melhor comportamento (nota média 5,83) que o Batatais, que, entre os cultivares de sequeiro plantados comercialmente, foi o mais suscetível (nota média igual a 6,67), semelhante ao controle suscetivel Agulha Precoce $(7,00)$.

As novas progênies de sequeiro mostraram, com raras exceções, alto grau de suscetibilidade à brusone nas folhas. Das 58 progênies testadas, apenas quatro foram suscetíveis em 33 ou $50 \%$ das vezes em que foram testadas, embora uma delas tenha apresentado nota média superior a 5,00. Cerca de 28 progênies foram suscetíveis em todos os locais em que foram testadas, mostrando comportamento idêntico ao controle suscetível. Oito e dezoito progênies foram suscetíveis em 67 e $83 \%$ dos testes respectivamente.

No quadro 2 são apresentados os resultados das reações dos $30 \mathrm{ma}$ teriais para plantio em condições irrigadas nas seis localidades.

Dentre os cultivares em plantio comercial, o IAC-120 teve o melhor comportamento, apresentando suscetibilidade em somente $50 \%$ das vezes em que foi testado. A seguir vem o Pinda F-3-7, suscetível em $67 \%$ das vezes, depois o Iguape Agulha, em 83\%. O 'IAC-435' e sua linhagem Pinda L-54 comportaram-se com suscetibilidade em todas as localidades onde foram testatados, à semelhança do controle suscetível (Agulha Precoce). 


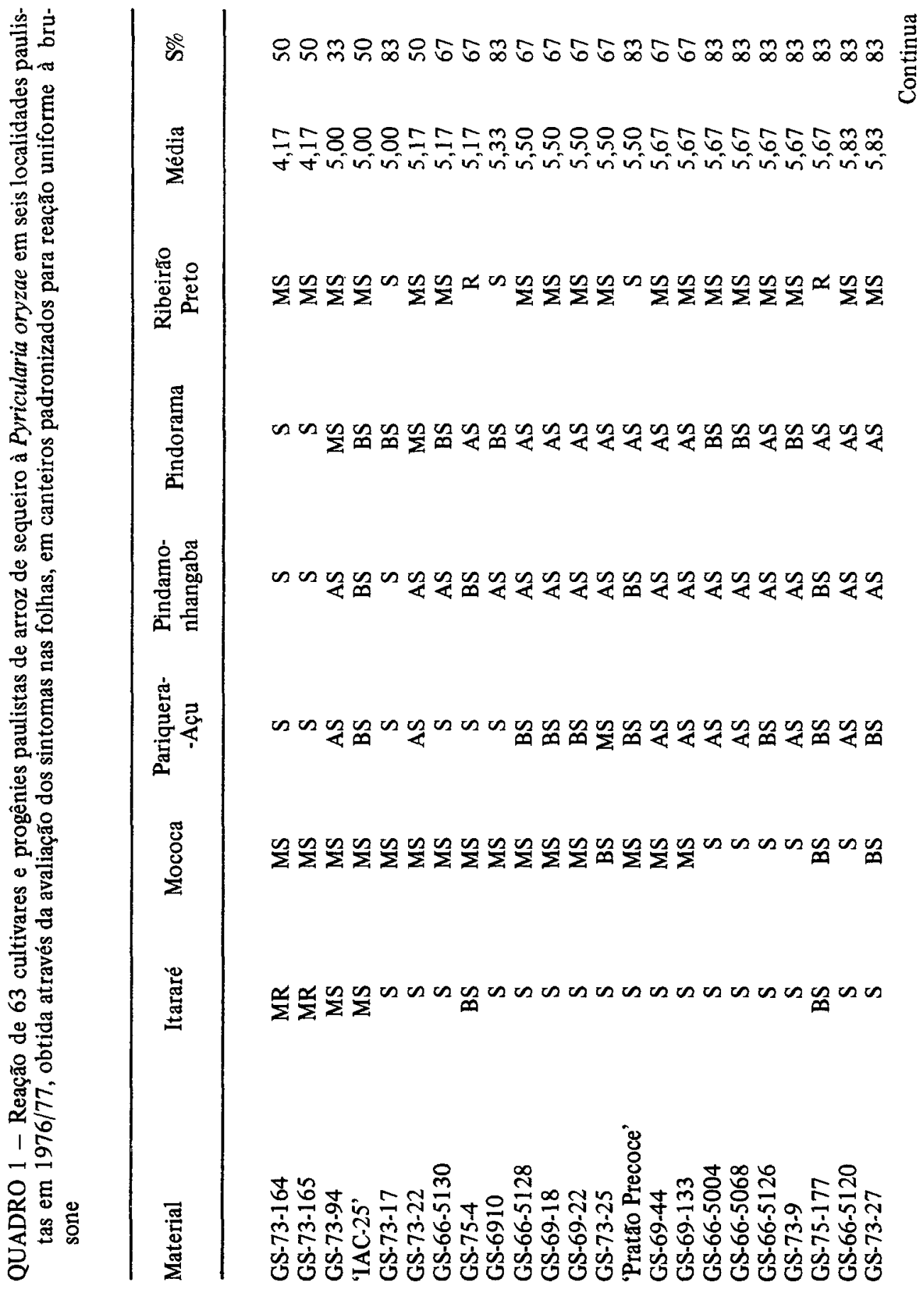




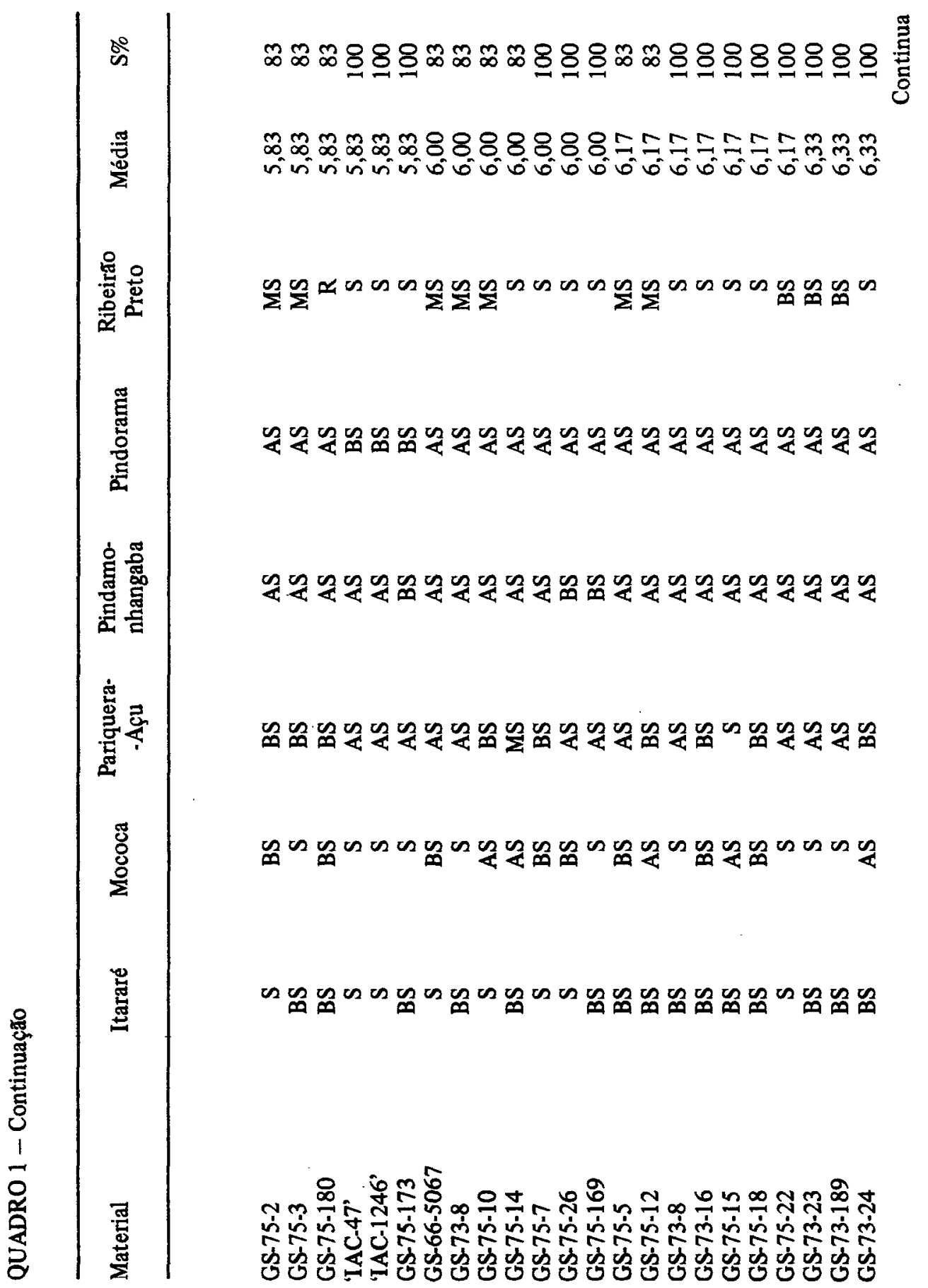




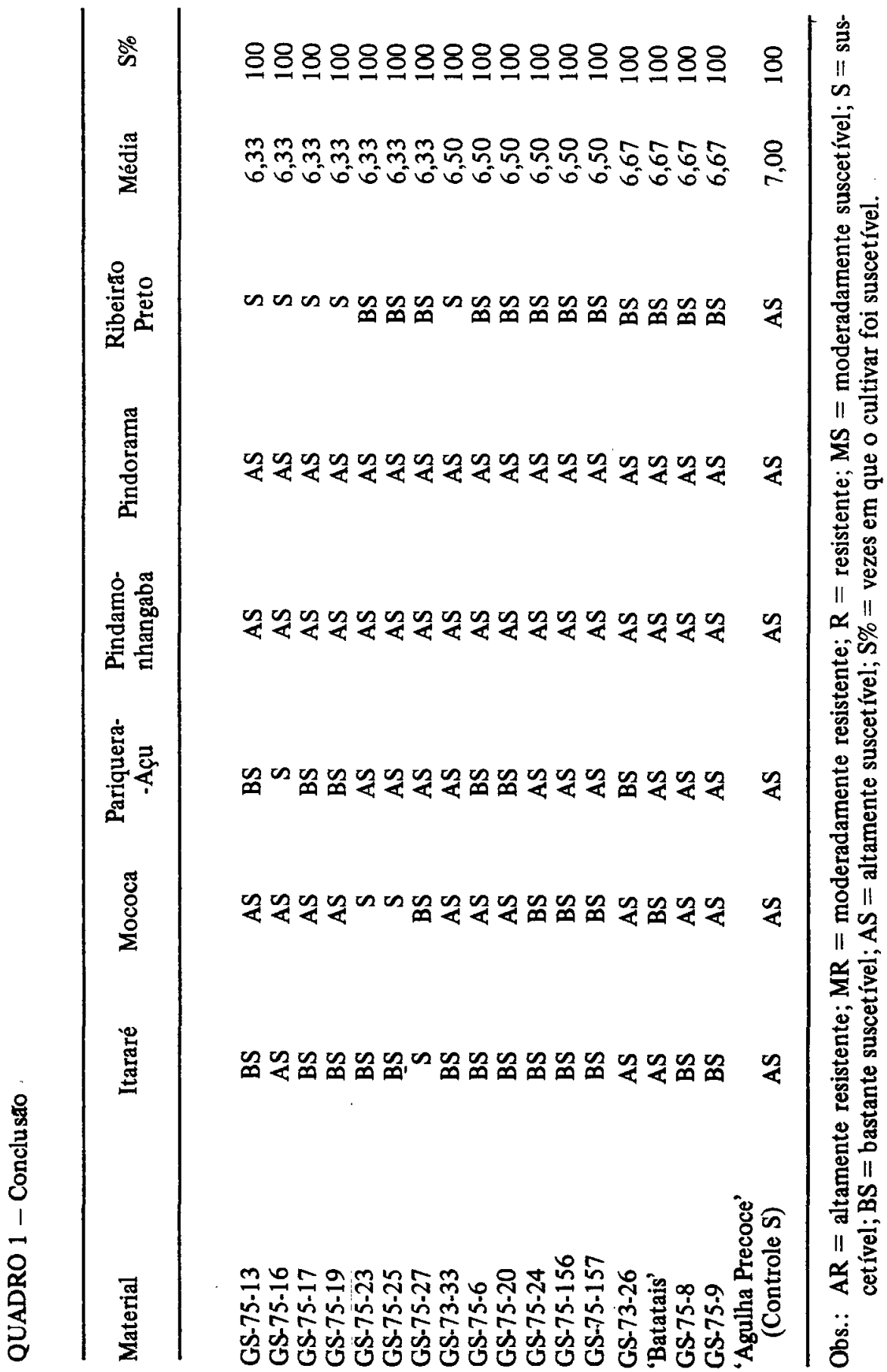




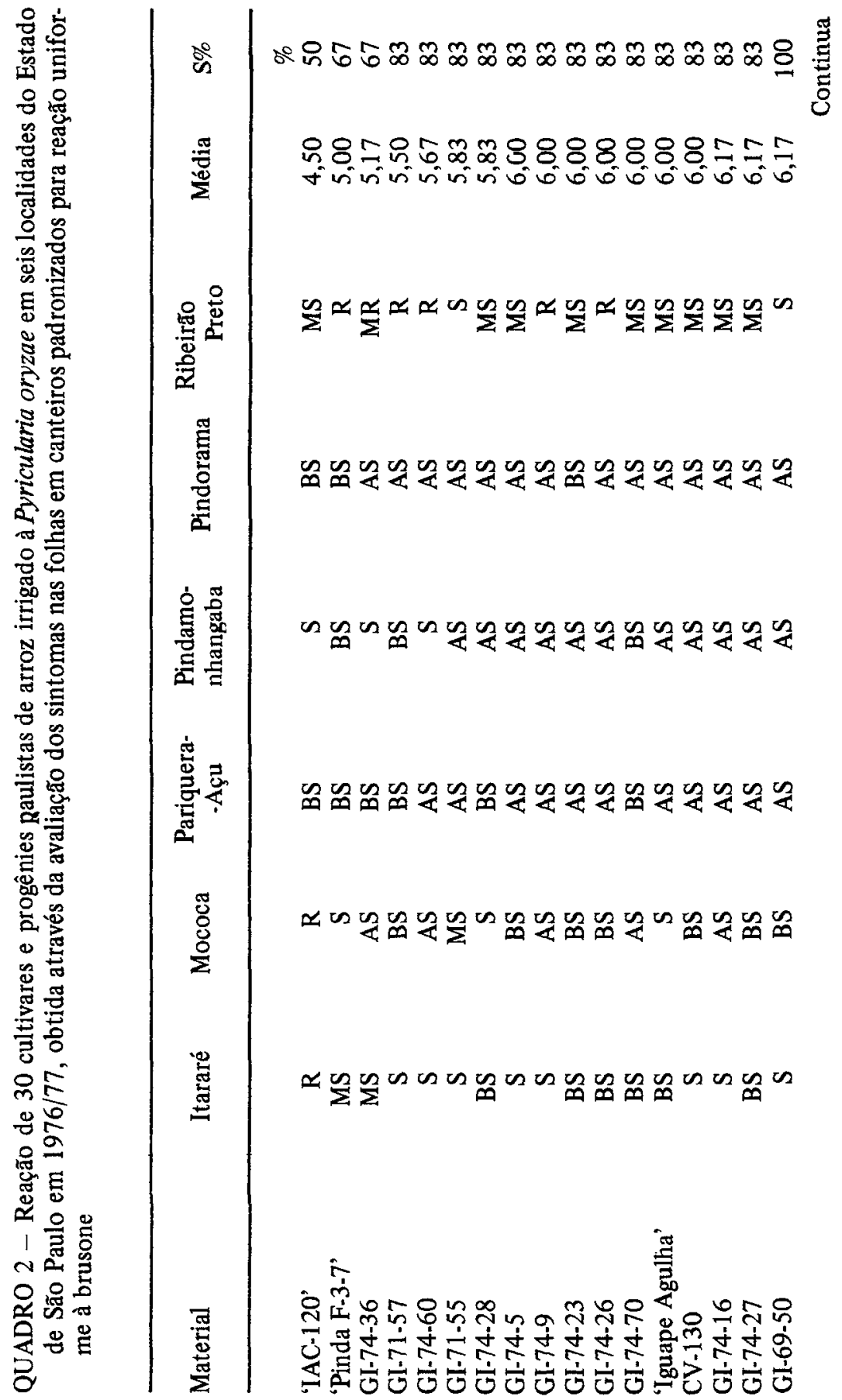




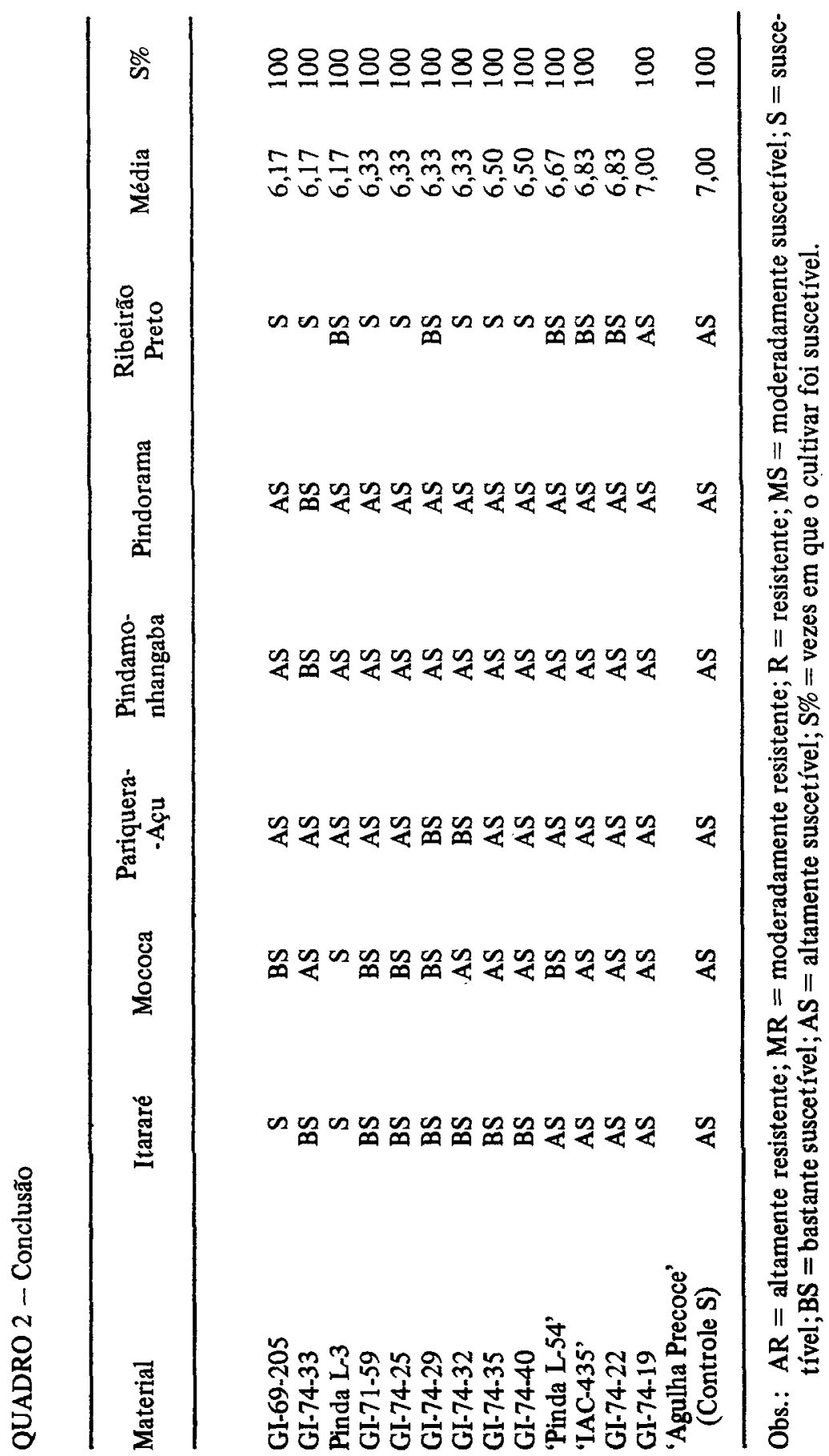


As novas progênies irrigadas também se mostraram bastante suscetíveis à brusone nas folhas. De um total de 25 progênies, uma foi suscetível em $67 \%$ dos testes efetuados, enquanto 13 linhagens se mostraram suscetíveis em $83 \%$ das vezes em que foram testadas. As demais progênies tiveram comportamento semelhante ao controle suscetível, apresentando suscetibilidade em todos os testes.

No quadro 3 estão alinhados os resultados do comportamento dos 102 cultivares/progênies exóticos de arroz à brusone na folha nas sete localidades paulistas. Desse total, 29 foram resistentes (notas 1,2 e 3) em todos os locais em que foram testados, 52 foram suscetíveis em $14 \%$ das vezes em que foram testados, 10 foram suscetíveis em $29 \%$ das vezes, $6 \mathrm{em}$ $43 \%, 1$ em $57 \%, 2$ em $71 \%$ dos locais em que foram testados. Dentre todos os cultivares, o IR-634-14-1-4 e o IRGA-407 não são recomendados como fontes de resistência por terem sido suscetíveis em todos os locais em que foram testados.

Em trabalho de avaliação da suscetibilidade de cultivares de arroz a $P$. oryzae, realizado por SOAVE et alii (1975) em 1971/72, em 1972/73 e 1973/74 (SOAVE et alii, 1976) e em 1974/75 e 1975/76 (SOAVE et alii, 1984), o 'Batatais' vem mostrando ser dos mais suscetíveis, e o 'Pratão Precoce', de menor suscetibilidade. Os dados obtidos no presente trabalho confirmam o comportamento de ambos os cultivares.

PRABHU et alii (1982) confirmaram que as variações de reação são maiores entre as localidades do que de um ano para outro, conforme SOAVE et alii (1978). Embora as variações de localidades sejam grandes, aquelas de um ano para outro também podem ser muito amplas, como vem ocorrendo com alguns cultivares. O IAC-1246 apresentou suscetibilidade em $100 \%$ das vezes em que foi testado em 1971/72 (SOAVE et alii, 1975). Em 1972/73 e 1973/74, conjuntamente, apresentou-se suscetível em $67 \%$ dos testes. Em 1974/75 (SOAVE et alii, 1984) foi suscetivel em 55\% das vezes em que foi testado e, no presente trabalho, foi suscetível novamente em $100 \%$ das vezes em que foi testado.

Dos cultivares recomendados para cultivo comercial de sequeiro, o IAC-47 vem apresentando maior suscetibilidade de ano para ano: Em 1971/72 (SOAVE et alii, 1975), apresentou suscetibilidade em 50\% das vezes em que foi testado, em 1972/73 (SOAVE at alii, 1976) em 73\%, em 1974/75 e 1975/76 (SOAVE et alii, 1984), em 83\%, e, em 1976/77, foi suscetível em $100 \%$ das vezes em que foi testado.

O cultivar IAC-25, que vinha apresentando estabilidade de reação em torno de $75 \%$ de reações suscetíveis (SOAVE et alii, 1975, 1976, 1984), mostrou uma tendência de diminuição de suscetibilidade para cerca de $50 \%$ de reações suscetíveis. 


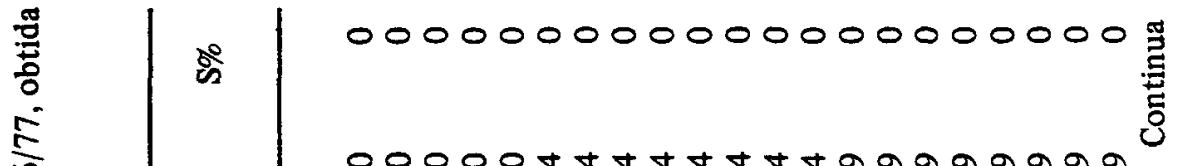

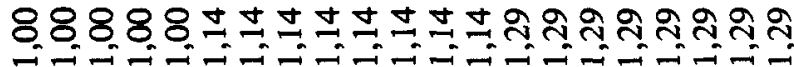

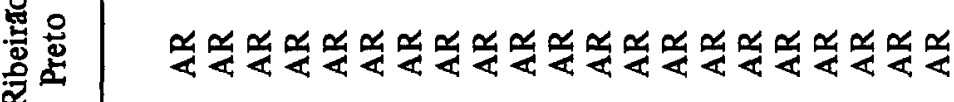

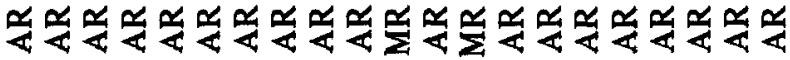

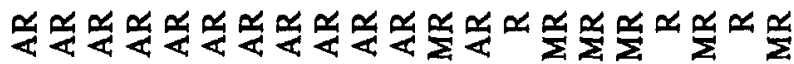

현

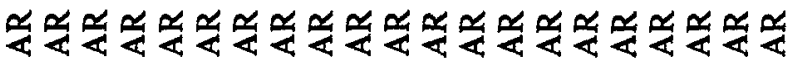

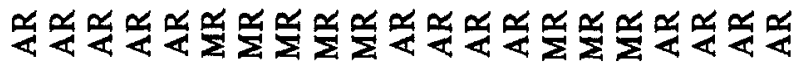

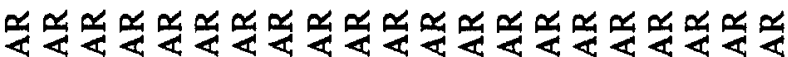




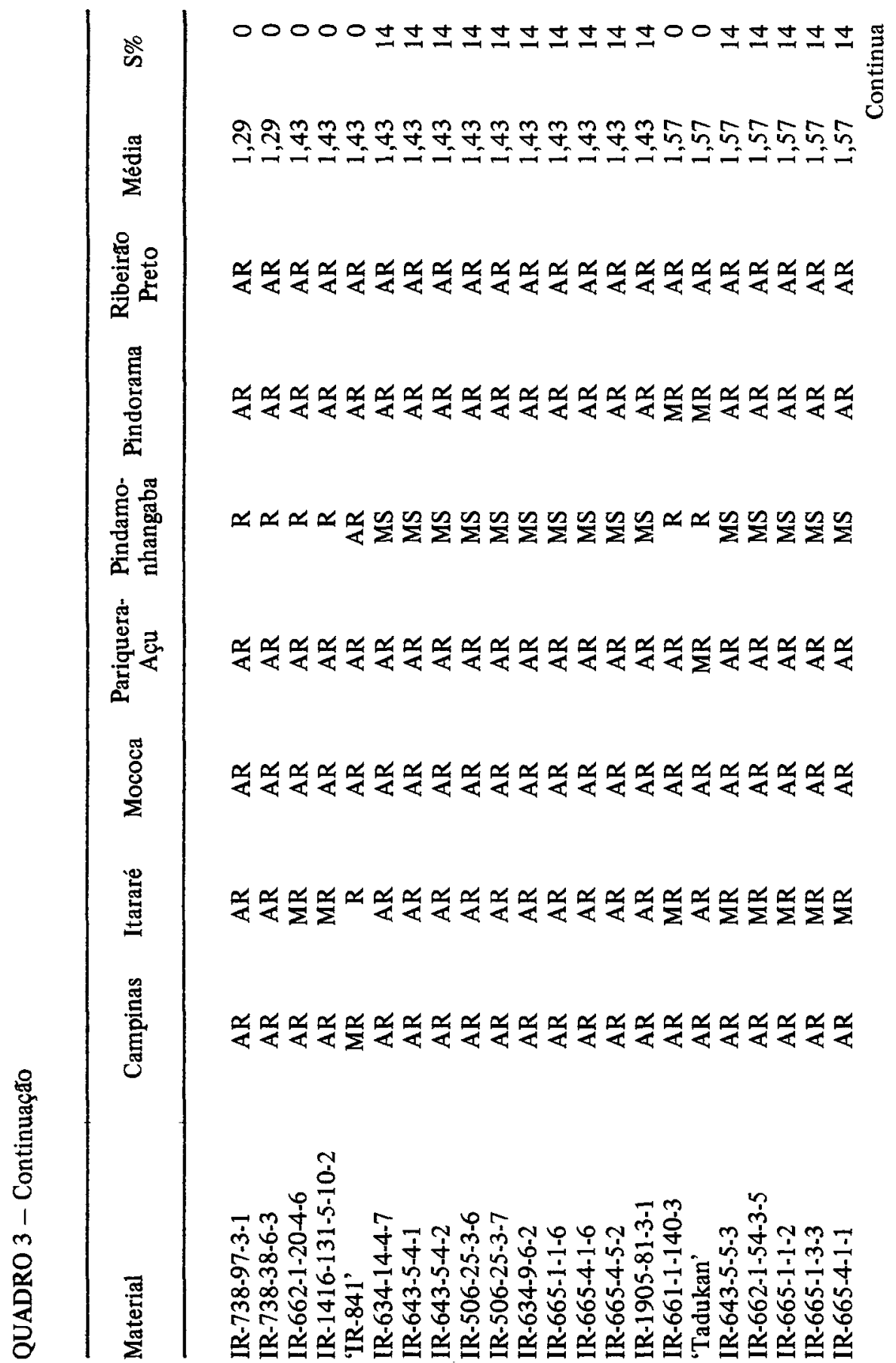




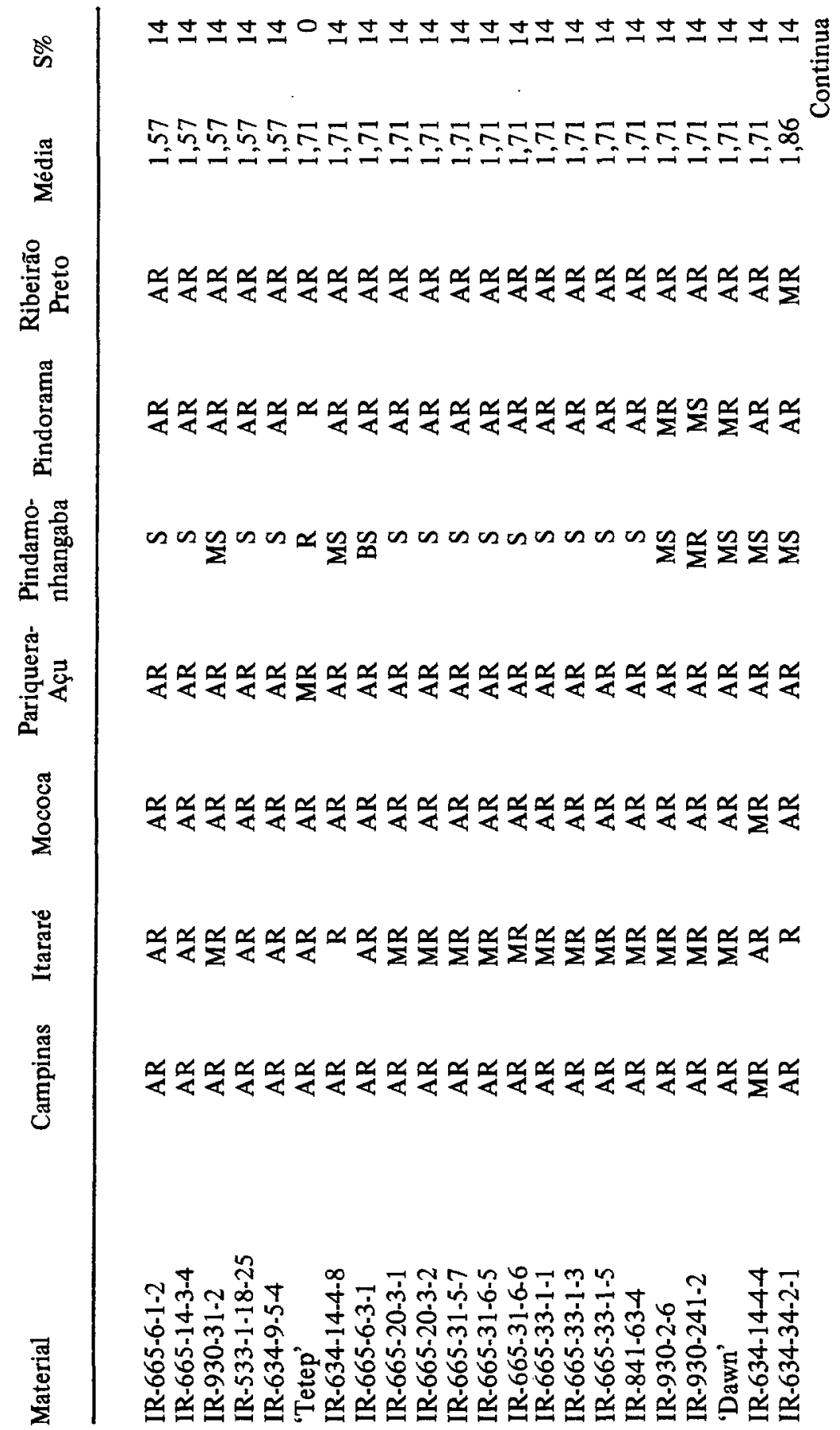




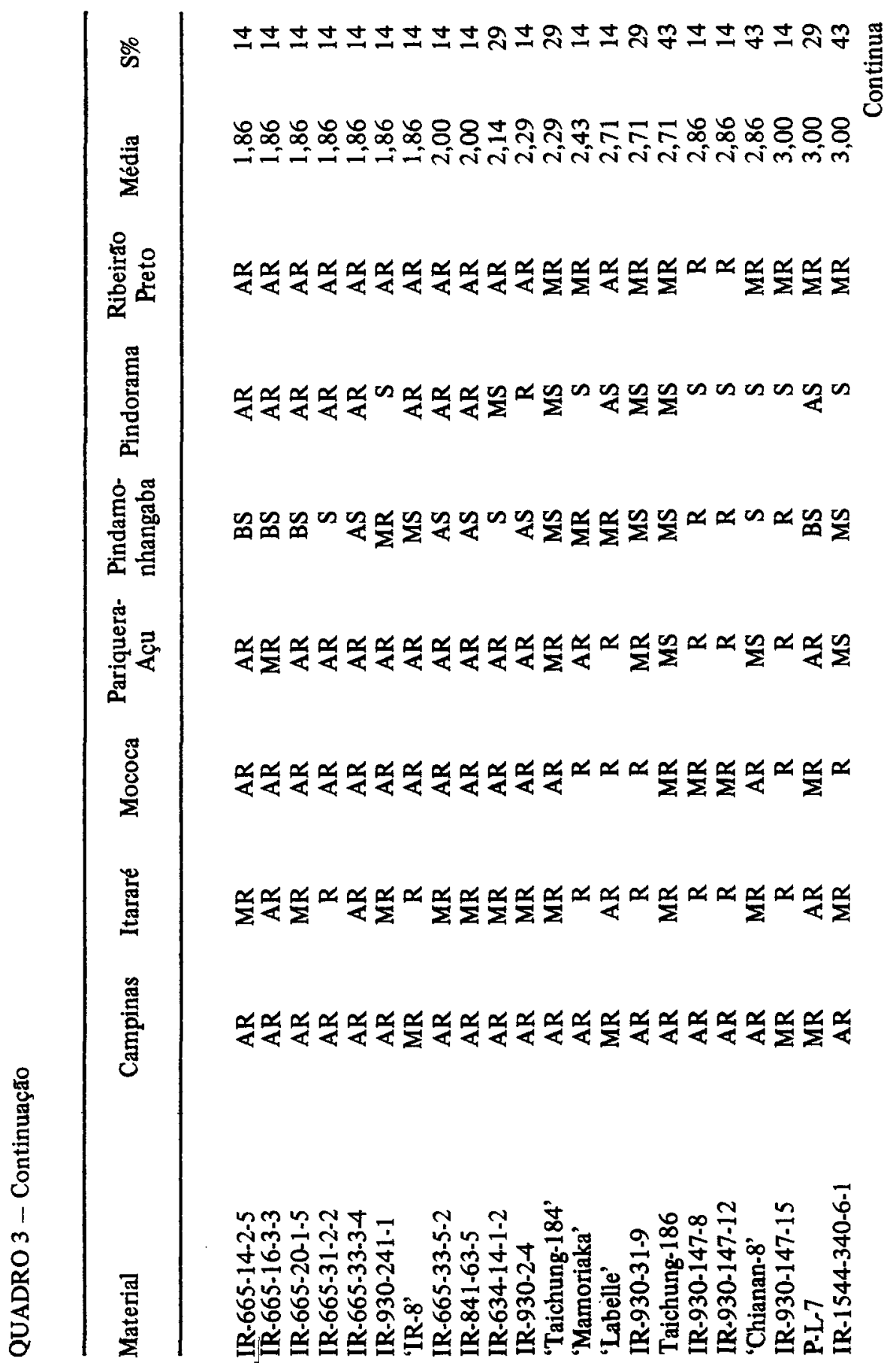




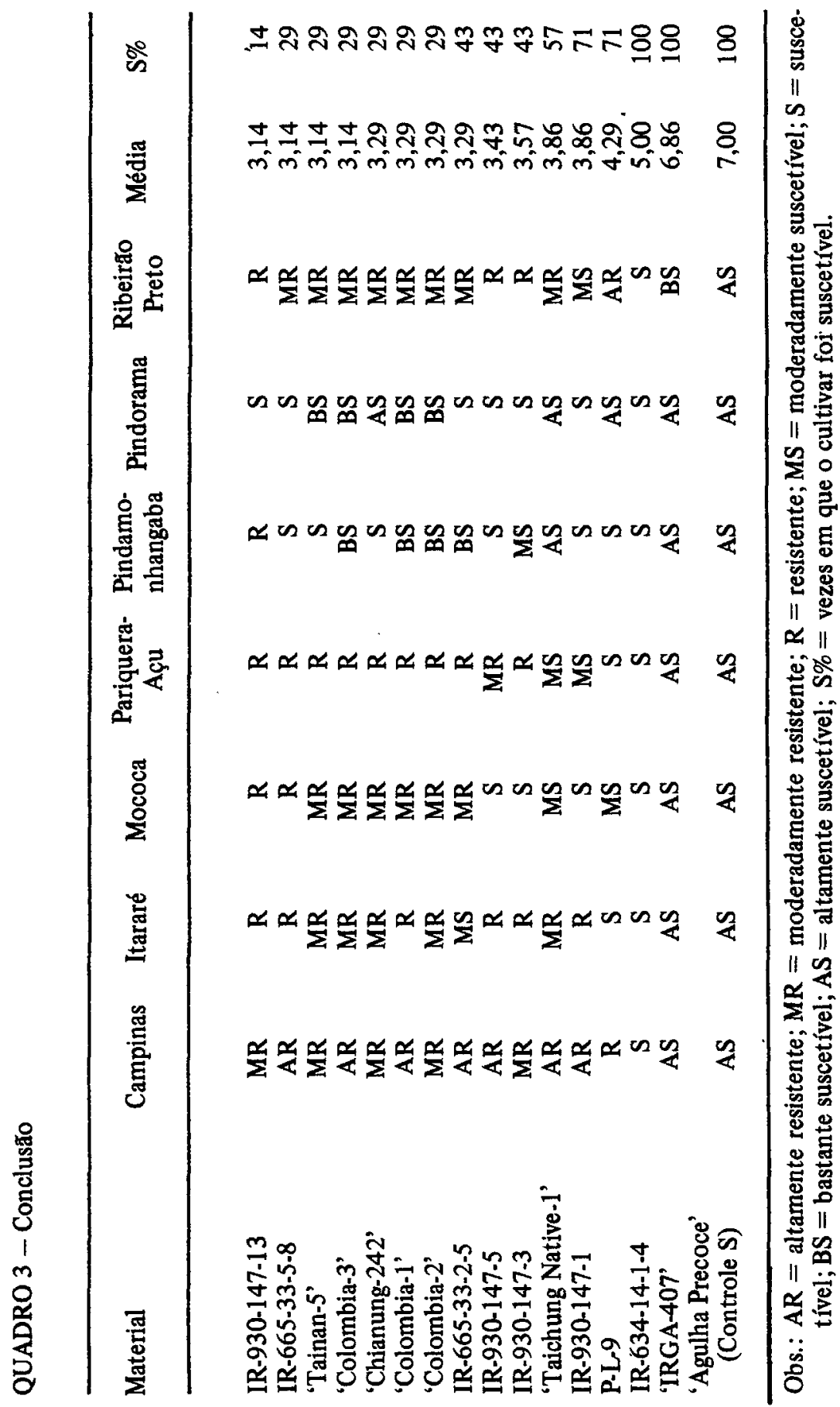


Essa variação anual de comportamento de um mesmo genótipo à brusone deve-se, provavelmente, à grande variabilidade genética do patógeno, causando a predominância de determinadas raças fisiológicas do fungo em anos específicos, conforme foi demonstrado por QUAMARUZZAMAN (1970).

Nenhum material, quer para cultivo em sequeiro, quer irrigado, foi resistente em todas as localidades em que foi testado, embora os seguintes, de sequeiro, tenham apresentado comportamento satisfatório quanto à brusone: GS-73-164, GS-73-165, GS-73-94 e 'IAC-25'. Por outro lado, quanto aos germoplasmas de irrigado, apenas os cultivares IAC-120 e Pinda F-3-7 mostraram bom comportamento quanto à brusone de folha.

Quanto aos genóticos exóticos testados visando detectar fontes de resistência a $P$. oryzae, procurou-se selecionar tipos que apresentassem reaçбes estáveis e espectro mais amplo de resistência, de maior interesse no melhoramento, conforme sugerido por OU \& JENNINGS (1969). Desse modo, os genótipos IR-4-93, IR-1813-694-2, IR-1542-43-2-1, T-1 e Carreon apresentaram-se altamente resistentes em todas as localidades em que foram testados, podendo ser indicados como as melhores fontes de resistência vertical à brusone. Essa resistência pode ser facilmente incorporada aos cultivares nativos (NELSON, 1973) ou, ainda, ser utilizada na criação de multilíneas (BROWNING \& FREY, 1969).

Os genótipos IR-930-31-10, IR-841-63-5-L-9-20, IR-841-63-5-L9-30, IR-1542-30-2-4-3, IR-946-14-3-3-2-3, 'Ram Tulasi', 'Umblatuzi V. Sugar Co.', 'Huan-Sen-Goo', IR-655-1-3-2, IR-822-432-2, IR-822-432-4, IR-930-31-3, IR-532-1-33, 'IR-22', 'IR-665', 'CICA-4', IR-738-97-3-1, IR-738-38-6-3, IR-662-1-20-4-6, IR-1416-131-5-10-2, IR-661-1-140-3, 'Tadukan' e 'Tetep' apresentaram reação de resistência em todos os locais onde foram testados, podendo também ser indicados como fontes de resistência à brusone no Estado de São Paulo, por possuir possivelmente genes que condicionam resistência vertical à doença. Os cultivares Tetep, Tadukan, Carreon e Ram Tulasi, mostraram espectro amplo de resistência, concordando com os resultados de PRABHU (1982).

\section{CONCLUSOEES}

1. Dos 63 genótipos de arroz para cultivo de sequeiro testados, somente os cultivares GS-73-164, GS-73-165, GS-73-94, IAC-25 e GS-73-17, embora suscetiveis, apresentaram comportamento satisfatório quanto à brusone. 
2. Dos 30 genótipos testados de arroz irrigado para cultivo, somente os cultivares IAC-120 e Pinda F-3-7, embora suscetíveis, apresentaram comportamento satisfatório quanto à brusone.:

3. Nenhum cultivar de arroz, tanto de sequeiro como irrigado, apresentou resistência em todas as localidades onde foram testados.

4. Os genótipos exóticos IR-4-93, IR-1813-694-2, IR-1542-43-2-1, T-1, 'Carreon', IR-930-31-10, IR-841-63-5-L-9-20, IR-841-63-5-L-9-30, IR-1542-30-2-43, IR-946-14-3-3-2-3, 'Ram Tulasi', 'Umblatuzi V. Sugar Co.', 'Huan-Sen-Goo', IR-665-1-3-2, IR-822-432-2, IR-822-432-4, IR-93031-3, IR-532-1-33, 'IR-22', 'CICA-4', IR-738-97-3-1, IR-738-38-6-3, IR-6621-20-4-6, IR-1416-131-5-10-2, IR-661-1-140-3, 'Tadukan' e 'Tetep' podem ser indicados como fontes de resistência à brusone no Estado de São Paulo.

\section{SUMMARY}

\section{IDENTIFICATION OF RESISTANT RICE PROGENIES TO LEAF BLAST DISEASE IN THE STATE OF SÃO PAULO, BRAZIL, IN 1976/77}

Local upland and lowland rice progenies and some exotic rice germplasms were evaluated with relation to leaf blast resistance. The tests were carried out in field conditions (natural inoculation) in standard nurseries for homogeneous reaction to leaf blast. The plants were evaluated according to the visual symptoms of the disease, and rated from one to seven, according to the degree system adopted in the "Symposium on the rice blast disease", in 1963. Sixty three upland and thirty lowland rice progenies were scored to leaf blast resistance in the following areas of the State of Sáo Paulo: Itararé, Mococa, Pariquera-Açu, Pindamonhangaba, Pindorama and Ribeirão Preto. Besides, one hundred and two exotic rice germplasms were tested in the same locations plus Campinas, looking for leaf blast resistance sources. Only five upland rice cultivars/progenies (GS-73-164, GS-73-165, GS-73-94, IAC-25 and GS-73-17) and two lowland rice cultivars (IAC-120 and Pinda F-3-7), although susceptible, performed quite well as related to leaf blast incidence. Twenty seven exotic varieties were indicated as good leaf blast resistance sources in the State of São Paulo.

Index terms: rice; blast; genetic resistance.

\section{REFERENCIAS BIBLIOGRÅFICAS}

AMARAL, R.E.M.; SOUZA, D.M.; MALAVOLTA, V.M.A. \& ISSA, E. Raças fisiológicas de Pyricularia oryzae Cav. no Estado de São Paulo. O Biológico, São Paulo, 45: 205-208, 1979.

BEDENDO, I.P.; RIBEIRO, A.S. \& CARDOSO, C.O.N. Variabilidade do fungo Pyricularia oryzae Cav. agente de brusone do arroz. Summa Phytopathologica, Piracicaba, 5: 106-109, 1979. 
BROWNING, T.A. \& FREY, K.J. Multiline cultivars as a means of disease control. Annual Review of Phytopathology, 7:355-382, 1969.

FRATTINI, J.A. \& SOAVE, J. Tentativa de avaliação das perdas causadas pelo brusone nas culturas de arroz no Estado de São Paulo. Revista de Agricultura, Piracicaba, 49:101-108, 1974.

IN'TERNATIONAL RICE RESEARCH INSTITUTE. Leaf lesion types of the rice blast disease adopted by the Symposium on the rice blast disease, In: The Rice Blast Disease. Baltimore, Maryland, John Hopkins Press, 1963. p. 450.

NELSON, R.R. Breeding plants for disease resistance, concepts and applications. London, Pennsylvania State University Press, 1973. 401p.

OU, S.H. A look at worldwide rice blast disease control. Plant Disease, 64: 439-445, 1980.

Rice Diseases. Kew, Surrey, England. Commonwealth Mycological Institute, 368p. 1972.

\& JENNINGS, P.R. The relation between leaf and neck resistance to the rice blast disease. International Rice Comission Newsletter, 12(4):30-35, 1969.

PRABHU, A.S. Sistema de produção de arroz de sequeiro visando o controle de brusone. Goiânia, EMBRAPA, Centro Nacional de Pesquisa de Arroz e Feijão, 1980. 15p. (Circular Técnica, 01)

; BEDENDO, I.P.; FARIA, J.C.; SOUZA, D.M.; SOAVE, J. \& AMARAL, R.E.M. Fontes de resistência vertical a Pyricularia oryzae em arroz. Summa Phytopathologica, Piracicaba, 8:78-90, 1982.

QUAMARUZZAMAN, M.D. \& OU, S.H. Monthly changes of pathogenic races of Pyricularia oryzae in blast nursery. Phytopathology, 60:1266$1269,1970$.

RIBEIRO, A.S. Prevalência de raças de Pyricularia oryzae Cav. no Rio Grande do Sul. Pesquisa Agropecuária Brasileira, Brasília, 15:175-182, 1980.

SOAVE, J.; AZZINI, L.E; BANZATTO, N.V.; SCHMIDT, N.C. \& ALOISI SOBRINHO, J. Reação comparativa dos principais cultivares paulistas de arroz (Oryza sativa L.) à Pyricularia oryzae Cav. em seis localidades do Estado de São Paulo, nos anos agrícolas de 1972/73 e 1973/74. Summa Phytopathologica, Piracicaba, 2:109-114. 1976.

; BANZATTO, N.V. \& ROCHA, T.R. Comportamento de cultivares de arroz quanto à suscetibilidade a Pyricularia oryzae Cav. em quatro localidades do Estado de São Paulo, em 1971/72. Summa Phytopathologica, Piracicaba, 1:87-91, 1975. 
SOAVE, J.; AZZINI, L.E.; BANZATTO, N.V.; SCHMIDT, N.C. \& ALOISI SOBRINHO, J. Reação comparativa dos principais cultivares paulistas de arroz (Oryza sativa L.) a Pyricularia oryzae Cav. em seis localizades do Estado de São Paulo, nos anos agrícolas de 1972/73 e 1973/74. Summa Phytopathologica, Piracicaba, 2:109-114, 1976.

; SCHMIDT, N.C. \& BANZATTO, N.V. Reação dos principais cultivares e progênies de arroz à brusone no Estado de São Paulo em 1974/75 e 1975/76. Fitopatologia Brasileira, Brasília, 9:59-65, 1984. 